\title{
Evaluation of the Impact of Government Policy on the Overuse of Groundwater in the Minqin Basin in China
}

\author{
Lihua Yang \\ School of Public Administration \& Workshop for Environmental Governance and Sustainability Science, \\ Beihang University, Beijing, China \\ Email: Journeyyang@yahoo.cn
}

Received January 31, 2013; revised March 2, 2013; accepted March 9, 2013

Copyright (c) 2013 Lihua Yang. This is an open access article distributed under the Creative Commons Attribution License, which permits unrestricted use, distribution, and reproduction in any medium, provided the original work is properly cited.

\begin{abstract}
The existing literature simply concludes that the irrational behaviors of local people and natural factors are the major reasons for overuse of groundwater. Using the OLS and ARIMA (BJ) Statistical Methods and Trend Analyses, this article finds that government policy, as measured by four proxy variables, is a very important factor that strongly influences the overuse of groundwater at the collective level. This means the government is a very important actor in the game of groundwater usage. Although these findings cannot clearly separate government effects from local effects, using a Trend Analysis, they reveal that these significant effects are strictly consistent with variations in government policy. Moreover, they show that government policy effective at the county level strongly impacts the overuse of groundwater by influencing the behavior of the local people and that policy at the operative level impacts four policy domains: population, cultivated land, water assignments and peasant income.
\end{abstract}

Keywords: Groundwater; Government Policy; Institutional Analysis; Institutional Change; Water Resources

\section{Introduction}

Minqin County, also called Minqin Basin in some academic articles, is said to be typical of many of the desert-oasis counties of inland China with its combination of pastoral and agricultural production regimes [1]. It is located in the northeast of the Hexi Corridor (the most important part of the old Silk Trade Road) on the lower reaches of the Shiyang River on the Alashan Plateau, bounded by the Tengger and Badain Jaran deserts, two large deserts in northwest China, in the east, west and north, and covers an area of 16,000 square kilometers. This area falls under the jurisdiction of Wuwie city (some 70 or $80 \mathrm{~km}$ from Wuwei) in central-eastern Gansu province and was once a natural barrier in the path of encroaching sand (see Figure 1).

Groundwater has been extracted on a large scale, particularly since the 1970s, to irrigate the Minqin oasis. On average, the annual pumping amounts to 0.722 billion $\cdot \mathrm{m}^{3}$ [3]; large-scale exploitation of the groundwater has been lowering the groundwater table by $0.6-1.0 \mathrm{~m}$ annually, and many wells have been discarded and replaced more than 5 times [4]. Harris's study concludes "consequently, the water table has fallen from 2 meters in the 1950s to 8 meters during the 1980s" [5]. The existing literature about the overuse of groundwater in Minqin has stressed seven factors: 1) population, 2) land reclamation, 3) decrease of water from the upper reaches (or the overuse of water in the upper reaches), 4) some economic development factors, including agricultural structure, increased livestock numbers, and overgrazing, 5) temperature, 6) precipitation, and 7) evaporation [1,6,7]. Here, we evaluate whether government policies also influence the overuse of groundwater.

\section{Modeling the Impact of Government Policy on the Overuse of Groundwater}

\subsection{The Dependent Variable and Data Description}

The overuse of groundwater is the dependent variable in this research, denoted $W$. Theoretically, the accurate measure of the overuse of groundwater should be the water table or the remaining amount of groundwater. However, because of a lack of scientific methodology and tech- 


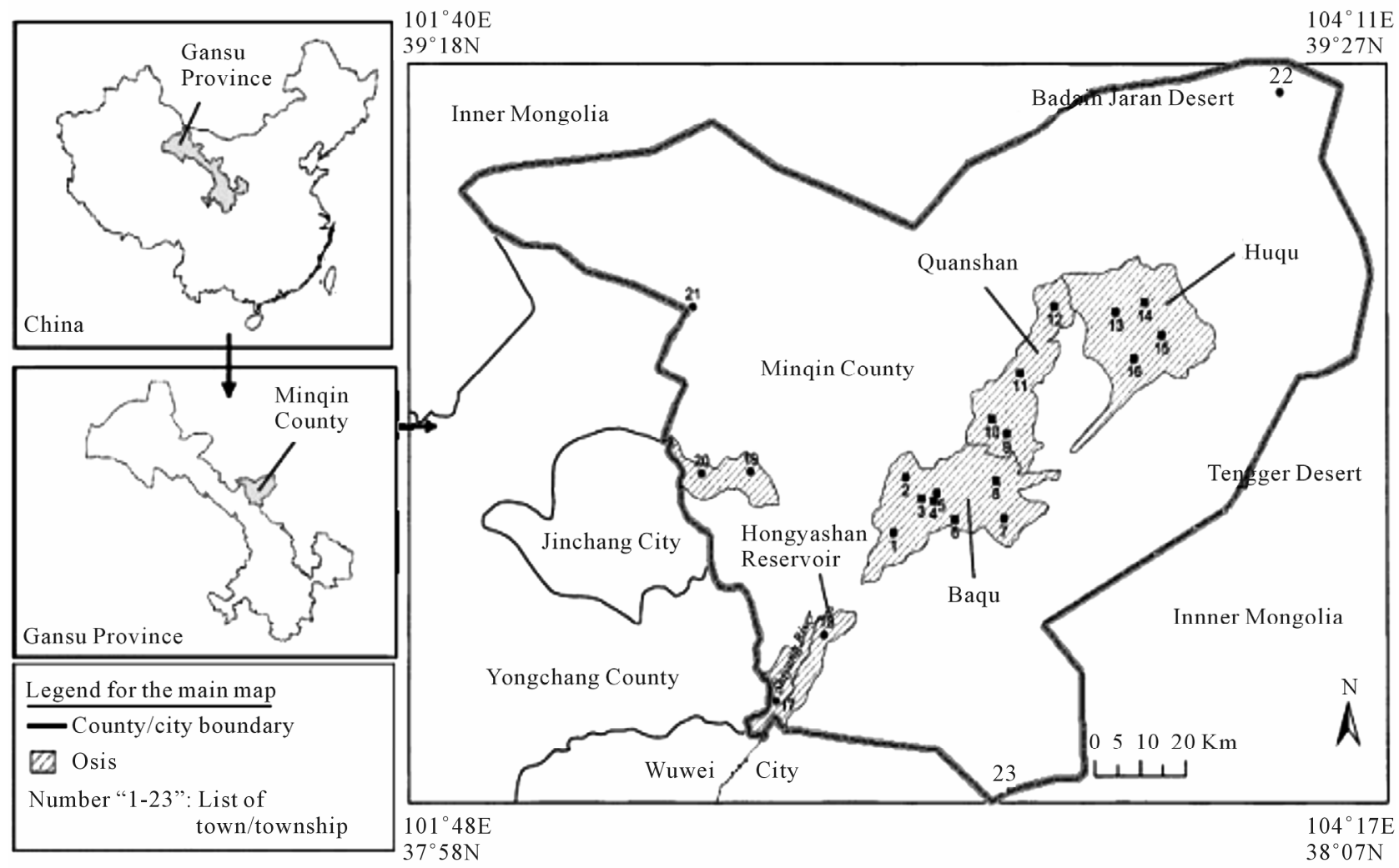

Figure 1. Map of Minqin County. Source: Adapted from the study by Lee and Zhang [2].

nological tools, these data have not been continually recorded in Minqin County. There is only information available for a few years. Therefore, we choose the average depth of wells (the unit is "m") as a proxy to measure the overuse of groundwater. Because the depth of the well depends on the water table, this proxy is a credible measure of overuse of groundwater. In addition, because the people in Minqin County mainly began to draw groundwater on a large scale starting in the 1960s, the annual data of the average depth of the wells from 1960 to 2004 was used in the analysis.

\subsection{Maintaining the Integrity of the Specifications}

Given the existing theories and studies mentioned above, we know that the major policies that strongly influence the use of groundwater mainly include the following: the population policy, the land policy, the water right policy, and the economic policy. We choose population (denoted as $P$, the unit is 10 thousand), the area of cultivated land (denoted as $L$, the unit is 10 thousand "mu"), the amount of water that flowed from the upper reaches (denoted as $F$, the unit is 0.1 billion $\cdot \mathrm{m}^{3}$ ) and the average peasant income (denoted as $I$, the unit is Yuan) as proxies to measure government impact. We deem them independent variables in the model. The annual data for these vari- ables from 1960 to 2004 are all available from the government gazette of Minqin County. Furthermore, the reason why we choose land and population as the major policy proxies is based on the fact that agricultural water use, domestic water use and water used by humans and animals account for the vast majority of the water use.

To control for other factors that may also impact the overuse of ground water, depending on the existing theories and studies mentioned above, we add the average temperature (denoted as $T$, the unit is "c"), the average precipitation (denoted as $R$, the unit is "mm") and the average evaporation (denoted as $E$, the unit is "mm") as the control variables. The annual data for these variables from 1960 to 2004 can also be obtained from the government gazette of Minqin County. Finally, because the groundwater system of Minqin basin is a relatively closed system in terms of the geological characteristics [8], we can ignore the effects of other factors, such as the movement of the groundwater under the surface.

\subsection{The Basic Research Model}

Using the denotations given above, our basic research model can be specified as follows:

$$
W_{t}=f\left(P_{t}, L_{t}, F_{t}, I_{t}, T_{t}, R_{t}, E_{t}\right)
$$

where $\alpha$ is the intercept, $\beta_{i}$ is the difference coeffi- 
cient, and $\varepsilon_{t}$ is the stochastic error term ${ }^{1}$. None of the data that will be used in this model is non-stationary. In a pre-study, we did a Dickey-Fuller test of unit roots and found the MacKinnon approximate $P$ value for $Z(t)=$ 0.9950 , indicating the unit root is problematic. Therefore, to technically eliminate some threats to the validity of our model caused by this attribute of the data, we develop the above variables as differenced forms. This is also reasonable because we suppose the differenced values of population, land, water, income and others are related to the differenced values of the overuse of groundwater. Thus, we now study the changes of independent values on the changes of dependent values. Then, a differenced model is created:

$$
\begin{aligned}
W_{t}-W_{t-1}= & \alpha+\beta_{1}\left(P_{t}-P_{t-1}\right)+\beta_{2}\left(L_{t}-L_{t-1}\right) \\
& +\beta_{3}\left(F_{t}-F_{t-1}\right)+\beta_{4}\left(I_{t}-I_{t-1}\right) \\
& +\beta_{5}\left(T_{t}-T_{t-1}\right)+\beta_{6}\left(R_{t}-R_{t-1}\right) \\
& +\beta_{7}\left(E_{t}-E_{t-1}\right)+\varepsilon_{t}
\end{aligned}
$$

That is:

$$
\begin{aligned}
\Delta W_{t}= & \alpha+\beta_{1} \Delta P_{t}+\beta_{2} \Delta L_{t}+\beta_{3} \Delta F_{t}+\beta_{4} \Delta I_{t} \\
& +\beta_{5} \Delta T_{t}+\beta_{6} \Delta R_{t}+\beta_{7} \Delta E_{t}+\varepsilon_{t}
\end{aligned}
$$

where $\Delta W_{t}=W_{t}-W_{t-1}, \Delta P_{t}=P_{t}-P_{t-1}, \Delta L_{t}=L_{t}-L_{t-1}$, $\Delta F_{t}=F_{t}-F_{t-1}, \Delta I_{t}=I_{t}-I_{t-1}, \Delta T_{t}=T_{t}-T_{t-1}$, $\Delta R_{t}=R_{t}-R_{t-1}$, and $\Delta E_{t}=E_{t}-E_{t-1}$.

Then, after doing the differenced translation, the data are still available for 44 years from 1961 to 2004 .

\section{Empirical Results and Analysis}

\subsection{The OLS Results}

Using the OLS method, the statistical results obtained from the STATA are shown in Table 1. The $R^{2}$ is 0.6951, and the adjusted $R^{2}$ is 0.6359 . Because one of the important assumptions of the classical linear regression model is that disturbances $\varepsilon_{t}$ are homoscedastic, we were initially concerned about heteroscedasticity. However, when a white test was done, the chi-squared value was 39.93708 and its $P$ value was 0.26 , indicating there is no strong evidence for the assumption that homoscedasticity is violated. To test whether there is a first order autocorrelation, a Durbin-Watson test was also done. The DurbinWatson d-statistic is 1.847752 , which means there is no significant evidence of first order autocorrelation. Gener-

\footnotetext{
${ }^{1}$ Some readers here may worry about the problem of multicollinearity. However, based on pre-studies, we found there is no perfect or very high multicollinearity. Furthermore, our task is to find whether the factors mentioned above are really impacting the overuse of groundwater, and it is therefore unreasonable for us to use the "dropping variables" method. Thus, we follow the thought of the "Do Nothing" or "God's Will" schools and leave this in our model. Then, the above simple linear function form is still a useful model for us to study the targeted topic.
}

Table 1. Government policy impacts on the overuse of groundwater using the OLS method.

\begin{tabular}{ccc}
\hline $\begin{array}{c}\text { Independent variables } \\
\text { (Differenced) }\end{array}$ & $\begin{array}{c}\text { Regression } \\
\text { coefficients }\end{array}$ & Standard errors \\
\hline Intercept & $0.8914002^{*}$ & 0.3255335 \\
Population $(P)$ & $2.888201^{* * *}$ & 0.5514038 \\
Area of cultivated land $(L)$ & $0.8832096^{*}$ & 0.3327417 \\
Amount of water that flowed & $-1.563346^{* *}$ & 0.4977644 \\
from the upper reaches & & 0.0025329 \\
Average peasant income $(I)$ & $0.0094834^{* *}$ & 0.4584166 \\
Average temperature $(T)$ & $0.1173247^{++}$ & 0.0059962 \\
Average precipitation $(R)$ & -0.012006 & 0.0015649 \\
Average evaporation $(E)$ & $-0.0036052^{*}$ & \\
$F$ statistic (7, 36) & $11.73^{* * *}$ & \\
$R$-squared & 0.6951 & \\
Adjusted $R$-squared & 0.6359 & \\
$\quad$ Root MSE & 1.6228 & \\
White’s general test statistic & $39.93708^{+}$ & \\
Durbin-Watson d (8, 44) & 1.847752 & \\
$N=44$ & & \\
\hline
\end{tabular}

Note: Significance levels are: ${ }^{* * *} P<0.001,{ }^{* *} P<0.005,{ }^{*} P<0.05 ;{ }^{+} P>0.1$, ${ }^{++} P>0.7$ (two-tailed).

ally, the coefficients of population $(P)$, the area of cultivated land $(L)$, the water amount that flowed from the upper reaches $(F)$ and the average peasant income $(I)$ are all significant. The $P$ values of population and peasant income are less than or about 0.001 , the $P$ value of the water that flowed from the upper reaches is less than 0.005 , and even the $P$ value of the cultivated land is also less than 0.05 . This means there is significant evidence that the population, the cultivated land, the water that flowed from the upper reaches and the peasant income strongly influence the depth of wells (a proxy of the overuse of the groundwater). Concretely, the population coefficient is 2.888201, which means that if the population increases by 10 thousand, the depth of the wells will increase 2.888201 meters on average, assuming the other variables remain constant. The coefficient of the area of cultivated land is 0.8832096, which means that if the cultivated land increases by 10 thousand "mu"s, the depth of the wells will increase 0.8832096 meters on average, assuming the other variables remain constant. The coefficient of water that flowed from the upper reaches is -1.563346 , which means the depth of the wells will increase 1.563346 meters on average when the water flowing from the upper reaches decreases by 0.1 billion $\cdot \mathrm{m}^{3}$, assuming the other variables remain constant. The coefficient of the peasant income is 0.0094834, 
which means, if the other factors remain constant, the depth of the wells will increase 0.0094834 meters when the income increases by 1 Yuan. By the same token, the depth of the wells will increase 0.94834 meters on average when the income increases by 100 Yuan. The connections between the population, the area of cultivated land and the water that flowed from the upper reaches and the overuse of groundwater are quite clear. However, some readers may wonder why the peasant income is related to the overuse of groundwater. When peasants have more money, they may dig more wells or dig the wells deeper to get more water, organize other programs that may use more groundwater, use more technology to reduce the water evaporation and other kinds of water loss, and so on, all of which are the facts of life in the Minqin basin.

As for the coefficients of the control variables, the results are different. The $P$ value of temperature is about 0.8 , which is very large, meaning there is no statistically significant evidence that the temperature is an important factor in the overuse of groundwater. This finding contradicts common sense. Figure 2(a) shows that over last 45 years, the temperature had an obviously increasing trend, which was consistent with the trend of global warming, and many scholars concluded from this that temperature was an important factor in the overuse of groundwater. The $P$ value of precipitation is about 0.053 , or roughly 0.05 . This suggests its impact on the overuse of groundwater is not significant at the level of 0.05 , but it is still significant at the significance level about 0.055, and its coefficient is -0.012006 . The negative number means that as the rate of precipitation increases, the well depth will decrease. The $P$ value of evaporation is less than 0.05 , and its coefficient is -0.0036052 , another negative number. This is somewhat surprising, as many people generally expect that evaporation will have a positive effect on the groundwater use. Our model may give a negative value for several reasons: first, as shown in Figures 2(b) and (c), we found that, in general, levels of precipitation and evaporation were relatively stable and changed little over the past 45 years. Second, although the evaporation had no obvious change over the past 45 years, the variation in the levels of evaporation exhibited a modest diminishing trend. Finally, at the beginning of the research period (in the early years of the 1960s), it had an extremely high value, but at the end of the research period (in 2001, 2002 and 2003), it had an extremely low value. These characteristics of the data may make the estimate of this particular coefficient inaccurate. Taken together as a total trend, the impacts of natural factors on the overuse of groundwater are not very significant, especially when we compare these effects to the effects of the four government policy proxy variables.

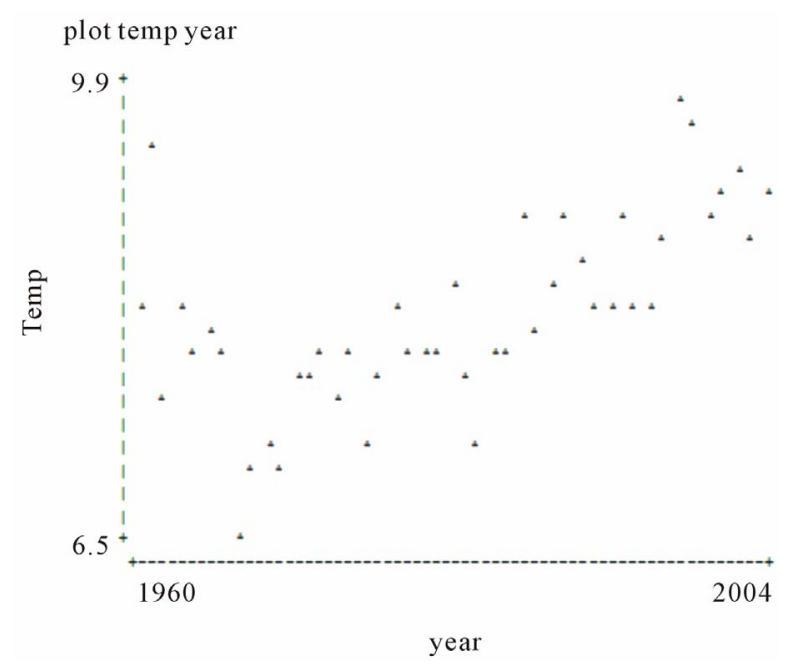

(a)

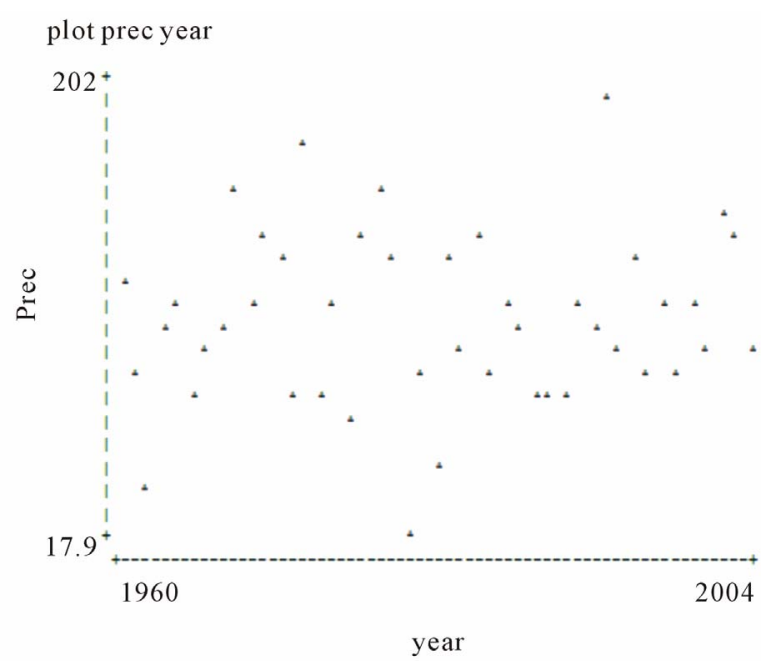

(b)

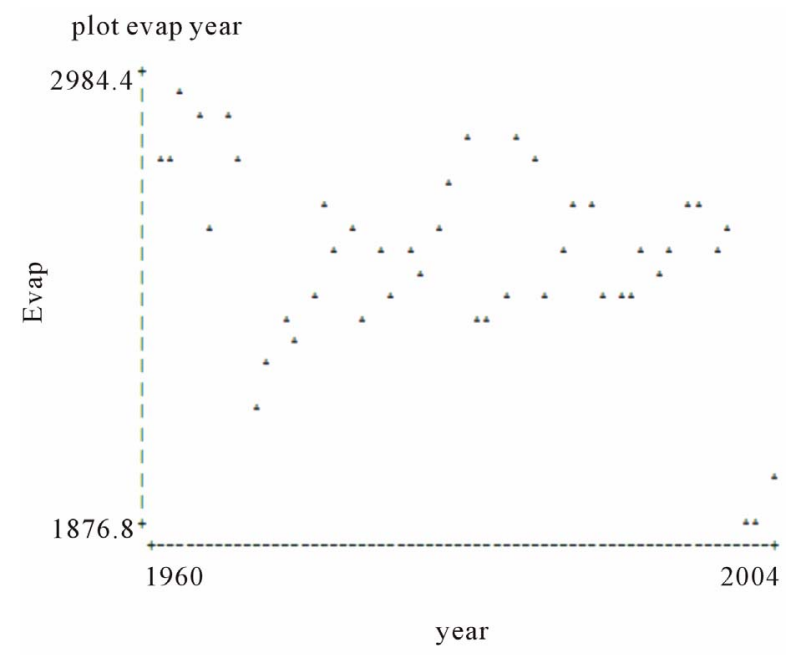

(c)

Figure 2. The change in temperature, precipitation and evaporation from 1960 to 2004. (a) Temperature; (b) Precipitation; (c) Evaporation. 


\subsection{The BJ Results}

As mentioned above, our original time series are nonstationary, that is, they are integrated. We know the emphasis of the Box-Jenkins (BJ) methodology, technically known as the ARIMA (Autoregressive Integrated Moving Average) methodology, "is not on constructing single-equation or simultaneous-equation models but on analyzing the probabilistic, or stochastic, properties of economic time series on their own under the philosophy let the data speak for themselves” [9], and after doing some pre-study, we found we have a time period which is stationary except for one difference. Therefore, to get a more accurate result from our model, the BJ methodology was used to identify and estimate our statistical model. The results obtained from the STATA are shown in Table 2.

From Table 2, we know the value of Wald Chi2 is 87.04, and its $P$ value is less than 0.001 . All the coefficients of our independent variables remain the same; only the standard errors and $P$ values are changed. The $P$ values of the intercept, the area of cultivated land, and the amount of water that flowed from the upper reaches are all less than 0.05 . The $P$ values of population and the average peasant income are both less than 0.001 . This represents a slight increase in the $P$ value of the amount of water that flowed from the upper reaches from less than 0.005 to 0.05 , but the $P$ value of the average peasant income decreases a little bit from less than 0.005 to less than 0.001. They all remain significant, however. By

Table 2. Government policy impacts on the overuse of groundwater using the $\mathrm{BJ}$ methodology.

\begin{tabular}{ccc}
\hline $\begin{array}{c}\text { Independent variables } \\
\text { (Differenced) }\end{array}$ & $\begin{array}{c}\text { Regression } \\
\text { coefficients }\end{array}$ & Standard errors \\
\hline Intercept & $0.8914002^{*}$ & 0.4094415 \\
Population $(P)$ & $2.888201^{* * *}$ & 0.5367814 \\
Area of cultivated land $(L)$ & $0.8832096^{* *}$ & 0.4331895 \\
$\begin{array}{c}\text { Amount of water that flowed } \\
\text { from the upper reaches }\end{array}$ & $-1.563346^{* *}$ & 0.7772646 \\
Average peasant income $(I)$ & $0.0094834^{* *}$ & 0.0026848 \\
Average temperature $(T)$ & $0.1173247^{++}$ & 0.567676 \\
Average precipitation $(R)$ & -0.012006 & 0.0085309 \\
Average evaporation $(E)$ & $-0.0036052^{*}$ & 0.0035872 \\
Wald Chi2 (7) & $87.04^{* *}$ & \\
Log likelihood & -79.32203 & \\
$\mathrm{~N}=44$ & & \\
\hline
\end{tabular}

Note: 1) Standard errors are given in parentheses beneath coefficients. 2) Significance levels are: ${ }^{* * *} P<0.001,{ }^{* *} P<0.005,{ }^{*} P<0.05 ;{ }^{+} P>0.1,{ }^{++} P>$ 0.8 (two-tailed). contrast, for our control variables, the $P$ value of temperature is larger than 0.8 , and the $P$ values of precipitation and evaporation are both larger than 0.1 , indicating that by the BJ methodology, none of the coefficients of our control variables are significant. These results also tell us that the proxies of the government policy are the important factors in the overuse of groundwater, whereas the effects of the three natural factors on the overuse of groundwater are not significant.

\section{Does Government Policy Really Impact the Overuse of Groundwater?}

\subsection{Trend Analyses and Government Policy Matching}

From the above analysis, we conclude that population, the cultivated land, the amount of water that flowed from the upper reaches and the peasant income all strongly influences the overuse of groundwater. But does this mean that government policies play an important role in the overuse of groundwater in Minqin? Some people may say these effects can also be attributed to the irrational behavior of the local people, on which most of the existing literature is premised, although this is often based solely on intuition. It may also be argued that although the government has some effect on these factors, the local people also influence these factors, and it may be impossible to separate the impact of government policy from local influence on groundwater overuse. Thus, it is important to determine which of these effects are caused by the government policy and to what degree. Essentially, however, the effects are the joint product of government policies and local behaviors because in general, government policies can only affect the overuse of groundwater by influencing local behaviors. Nevertheless, we believe these effects strongly reflect government policy based on two facts: first, as mentioned above and discussed in the next section, in a non-democratic political system, the behavior of the local people is always strongly managed and influenced by government policies. Second, there is a strict consistency between the variations of the government policies and the variations of our four proxy variables. This suggests the variations in our four proxy variables are really caused by and relatively strictly controlled or at least strongly influenced by the government and its polices. Certainly, the effects of local behavior on the overuse of groundwater can be deemed to be government policy effects on the overuse of groundwater. In this section, we assess the validity of these statements. To study this problem, we evaluate whether the variables used in our model are suitable proxies for government policy.

In terms of population, we know that the Chinese population was strongly influenced by political factors 
during Mao’s era from 1949 to 1976, and China has had a one-child policy since 1974 . Thus, the population is strictly controlled by government, except for some natural factors. This can be seen in Figure 3(a). From this figure, we see from 1960 to 1964, the population dramatically decreased in Minqin County. This is due not to natural factors but to the failure of Mao's Great Leap, which left numerous peasants dead. Then, the government began to strongly encourage the peasants to bear more children to compensate for the population gap caused by the tragedy of Mao's Great Leap policy. Accordingly, after 1964, the population in Minqin began to increase again until 1976. During this period, one strange phenomenon should be considered: after a high rate of increase in 1968, the population suddenly decreased in 1969. This can also be explained by government policy because in this year many people died or moved to other places due to the political movement of the Expansion of the Anti-right Movement during the Great Cultural Revolution. After 1973, and even more so after 1975, the sharp increase in population ceased until 1983. This was a result of the one child policy in effect in Minqin County beginning in 1973 and in full force from 1975. From 1984 to 1989, the population did not increase very fast and had two stages-1984 to 1986 and 1987 to 1989 - which reflected the implementation effects of the one child policy under different governmental leaders. In the 1990s, the population also increased relatively quickly because young men born between 1965 and 1973 began to have their own children. At this point, the government encouraged the people to bear more children according to Mao's philosophy "the more people, the better". After 1999, this increase was stopped due to the one child policy and government-mandated emigration of peasants because of the serious desertification in Minqin County.

With regard to the amount of water that flowed from the upper reaches, as is clear from Figure 3(c), the trend was continually decreasing. This trend is largely due to government policies. We can see that from 1967, the amount of water was dramatically decreased until the early years of the 1980s, and the speed was very fast. This is the result of many reservoirs being built after the Hongyashan reservoir was built in line with the government policy encouraging peasants to build more reservoirs to develop the economy. Much water was stored in these upper reach reservoirs, and the water use of the upper reaches also dramatically increased. Table 3 shows some information about the exploitation of the water resources in the Shiyang River watershed. This table tells us the increases in population, irrigation area, number of reservoirs, amount of water in the reservoirs, length of the canals, surface water flowing in the canals and the water efficiency of the canal system from 1949 to 1995 are all consistent with the decrease in the amount of wa- ter that flowed from the upper reaches in Minqin.

The area of cultivated land is also strongly affected by government policy. Figure 3(b) shows that from 1964 to 1975, due to the Great Leap and the Great Cultural Revolution, many peasants died and more people took part in the political movement, leaving cultivated land fallow. This trend stopped in 1976 with the death of Mao Zedong, and the influence of the political movement on the peasant life diminished. Then, from 1976 to 1979, the area of cultivated land began to increase. However, beginning in 1980, due to the reform and opening up policy after Deng Xiaoping became the new leader of China in 1978 , some cultivated land was used for city construction, and the total cultivated area decreased until 1984. It then increased again until 1988 because of new economic policies conducted by the central and local governments. At that point, the agricultural structure of Minqin became stable and governments also began to devote attention to industrial development in cities, so peasants could not cultivate more land. After 1992, due to the overheated economy effect from 1992 to 1995 especially in 1993 and 1995 after Deng Xiaoping's peak in 1992 in Southern China, more land was cultivated, particularly in 1993 and 1996, and this trend continued until 2000. After 2000, the policy of converting the land for forestry and pasture had to be conducted by the government according to Zhu Rongji, the new leader of the State Council of China, so the area of cultivated land continually decreased. This policy was continued when Hu Jingtao and Wen Jiabao became the new leaders of China in 2002.

Peasant income is also strongly influenced by government policy. From Figure 3(d), we see there was almost no change in the average peasant income from 1960 to 1979 before the reform and opening up policy was implemented, due to the policy failures of Mao's era and too many political movements. From 1980 to 1993, although the overall trend of the average peasant income increased after Deng Xiaoping became the real leader of China, its pace was not fast. The increase had three different levels: 1980 to 1985, 1986 to 1989, and 1990 to 1993, all of which are completely consistent with the government economic patterns and reform steps from 1980 to 1993 in China, including different economic reforms, the overheated economic conditions, and important political events. From 1994 to 1997, peasant income rapidly increased, but this was due to the overheated economy effect after Deng's peak in 1992 as mentioned previously. From 1998 to 2001, the increase was less rapid, as the government focused on the problems of state-owned firms when Jiang Zeming and Zhu Rongji were the real leaders of China. From 2002 to 2004, pace picked up again and incomes increased quickly because the new peasant policy had been implemented to increase peasant income after Hu Jingtao and Wen Jiabao became 


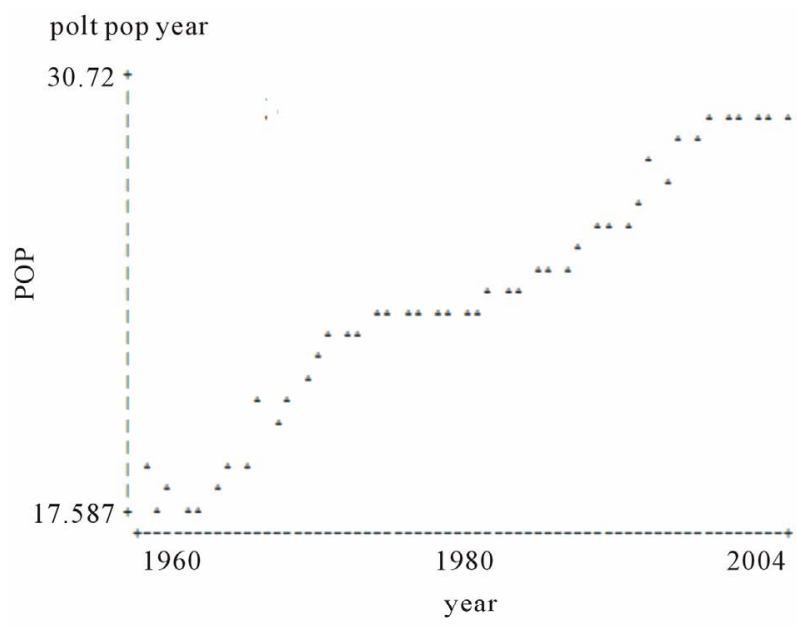

(a)

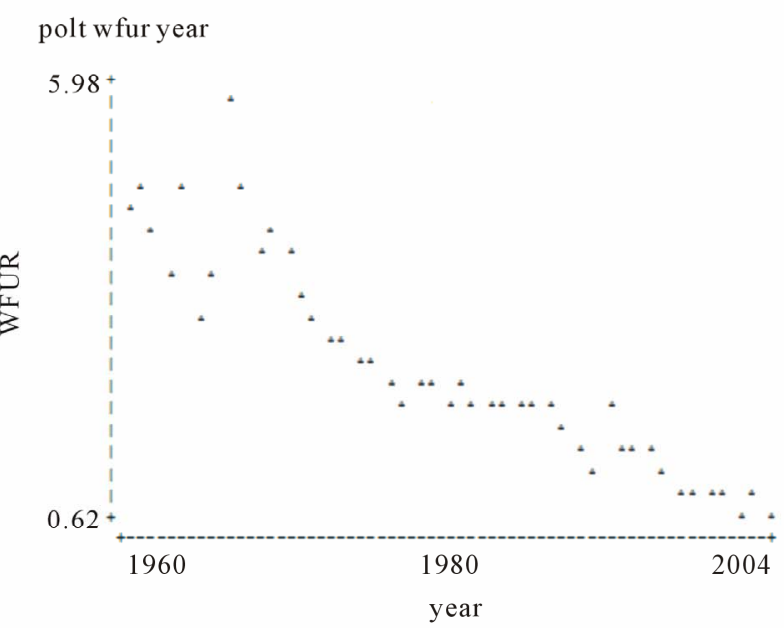

(c)

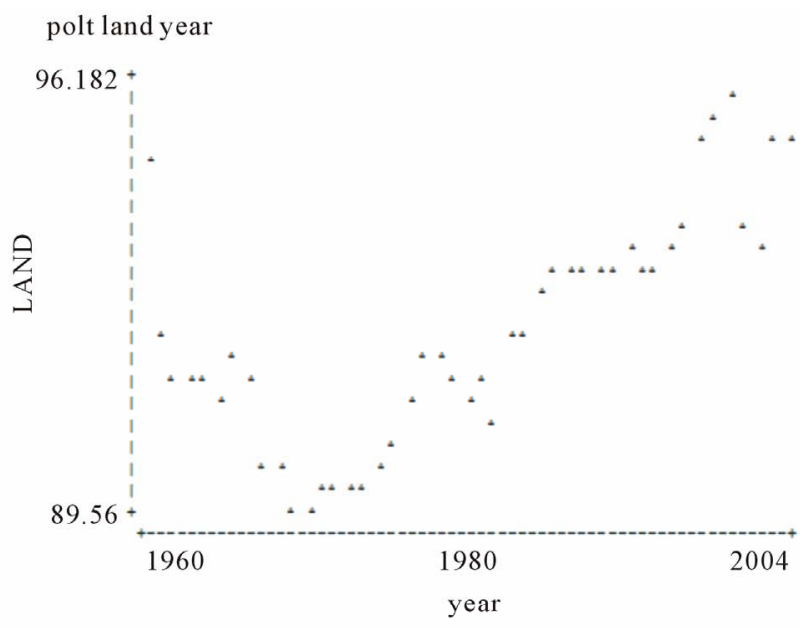

(b)

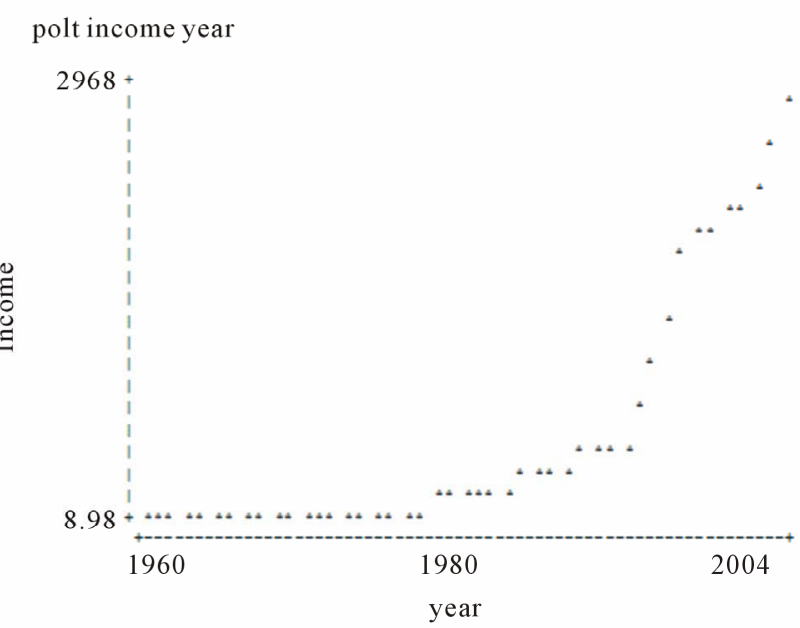

(d)

Figure 3. Change in population, cultivated land, amount of water that flowed from the upper reaches and peasant income from 1960 to 2004. (a) Change in population; (b) Change in cultivated land; (c) Change in the amount of water that flowed from the upper reaches; (d) Change in peasant income.

Table 3. Exploitation of water resources in the Shiyang River watershed.

\begin{tabular}{|c|c|c|c|c|c|c|}
\hline Time & 1949 & 1959 & 1972 & 1979 & 1985 & 1995 \\
\hline Population/ $\left(\times 10^{6}\right)$ & 0.9 & 1.08 & 1.1 & 1.43 & 1.55 & 2.2 \\
\hline Immigration area/( $\left.\times 10^{5} \mathrm{~km}^{2}\right)$ & 1.34 & 1.55 & 2.07 & 2.44 & 2.72 & 3.03 \\
\hline Number of reservoirs & 0 & 4 & 22 & 22 & 22 & 23 \\
\hline Amount of water in reservoirs $/\left(\times 10^{8} \mathrm{~m}^{3}\right)$ & 0 & 0.54 & 2.34 & 2.71 & 3.09 & 4.5 \\
\hline Length of canals $/ \mathrm{km}$ & 30 & 82 & 200 & 2046 & 2849.2 & 6716 \\
\hline Surface water flowing in canals $/\left(\times 10^{8} \mathrm{~m}^{3}\right)$ & & 1 & 2 & 11.4 & 11.5 & 14.1 \\
\hline Water efficiency of canal system/\% & 20 & 35 & 45 & 50 & 58 & 65 \\
\hline Number of wells & 0 & 0 & 582 & 11,700 & 121,000 & 142,000 \\
\hline Amount of groundwater exploitation/ $\left(\times 10^{8} \mathrm{~m}^{3}\right)$ & 0 & 0 & 4.76 & 8.95 & 10.3 & 11.6 \\
\hline
\end{tabular}

Source: Zhao et al. [10]. 
the new leaders of China in 2002.

In sum, from the analyses above, we found the variations of our four proxy variables are consistent with the government policy variation, particularly the central government policy variations. Thus, we can safely conclude that the four proxy variables in our model are indeed suitable proxies for government policy. It could be argued that these kinds of rough matching analyses are not reliable, but our answer is, if only one or two periods of the trends of different proxy variables match the government policy variation, this challenge would be reasonable. However, from the above analyses, we have seen that these matches are systematic and strict, indicating the reliability of the proxies. Furthermore, in the absence of more accurate data or more concrete information, and because of the difficulty of a continued statistical analysis in this domain, although there may be some caveats that will reduce the credibility and the causal validity of these analyses, this method is still a good choice to find the causal relationship between the proxy variables and the related government policies, and statistically and theoretically, these analyses are valuable.

\subsection{The Government Itself Is the Problem}

From the above analyses, we can conclude that, although we cannot clearly separate local effects from the effects showed by the four policy proxy variables, we do find the variations of these four policy proxies are highly consistent with the variation in government policy. This means that the four variables we chose to study in our basic model are credible proxies and indexes for government policy. Because the coefficients of these proxies are all significant, which means these factors strongly influence the overuse of groundwater, we can conclude that government policy really impacts the overuse of groundwater, which means the government itself is actually the problem despite its real and original desire to resolve the problem. This finding is consistent with E. Ostrom's arguments [11] that there is nothing special about the state, which is deemed as "the political science equivalent of Isaac Newton's recognition that the moon was falling” [12].

The effects of government policy on the overuse of groundwater can be divided into three basic dimensions. First, the government polices themselves are the institutions at the constitutional choice level or the collective choice level. The constitutional level institutions comprise the related government policies made by the central government in Beijing. The collective level institutions comprise the related government policies directly created by the provincial or county governments themselves. Second, the government policies create the new collective level institutions or change the old ones, like the implementation rules or polices made, chosen or changed by the provincial or county level governments under the requirement or directions of the central government policies, or the implementation rules, strategies, and concrete policies made, chosen or changed by the county level governments following the directions of the provincial rules created by the provincial policies. Third, the above two kinds of institutions create or change the operative level institutions or rules used by the locals. For example, the local peasants often should decide concrete rules, strategies under the large rule framework created by the constitution and collective level rules based on related government policies. Certainly, these rules and institutions, as a language-based phenomenon, cannot impinge directly on the real world [13]. However, by affecting the shared understandings of individuals making choices within decision situations, they impact the actors of decisions, the information structure, actions and their sequences, etc. [14]. As to the process, like Kiser and E. Ostrom [13] argued, these effects also have three steps: "First, the individuals affected by a change in rules must be cognizant of and abide by the change. Second, institutional change has to affect the strategies they adopt. Third, the aggregation of changed individual strategies must lead to different results” (1982: 56-57).

Although three levels of institutions always interact each other, within a non-democratic political system, the locals have little rights and power, and because there is little or asymmetric information to impact the other institutional creators like the bureaucrats in central, provincial and county governments, the operational level rules have little or no effect on the collective and constitutional institutions. This means that within a hierarchical and politicized system, the interaction directions of different levels of institutions are limited. Typically, only the strongly top-down effect exists, and the bottom-up effects do not. In such a system, "those who are assigned prerogatives to govern are assigned prerogatives that radically unequal to those who are subject to rules... Attributes of justice ascribed to equality under law say nothing of the inequalities between those who exercise governmental prerogatives and those who are subject to governmental prerogatives". Similarly, "the radical inequality between rulers and ruled is reinforced by the use of sanctions as instruments for enforcing rules” (V. Ostrom 1980: 384) [14]. This is the very reason why the behaviors of the local people and operative rules for using groundwater are strongly influenced by the two higher level rules, but they seldom have any effects on the higher level rules. Certainly, this is also the reason why we say local behavior and operative rules for using groundwater are strongly impacted by government policies. In this situation, all the locals can do is develop some new rules and strategies to try to adopt or comply 
with the collective and constitutional rules. If these kinds of behaviors lead them to pay too high a cost and they cannot or do not want to bear this cost, they will try to shirk or avoid the limitations of the exogenous rules, although sometimes these behaviors also have high costs and risks. If the collective and constitutional level rules are developed to try to limit the overuse of groundwater, these sequential strategies may lead to more serious problems of overuse of groundwater. In particular, if the collective level and constitutional level institutions are changed to try to eliminate these locals following operative rules, the locals have to find other new strategies and form new potential operative rules to avoid the new negative effects on them by these exogenous institutions. Thus, a paradox of an institutional competition game appears. However, in this competition game, the actors often pay a much higher cost, and it will often deteriorate the conditions of the CPR (common pool resources), which has been proven by the overuse of groundwater in the Minqin basin.

\section{Conclusion}

Chinese scholars and officials often overestimate the capability and knowledge of the locals and other entities, such as the enterprise, to resolve environmental problems after 1949. Therefore, they often assume the behaviors of the local people are to blame and deem them responsible for environmental problems, such as the overuse of groundwater [15]. However, the findings in this article show that the overuse of groundwater has been strongly affected by government policy in the Minqin basin after 1960. Because of the lack of the relevant, accurate data, this article uses proxy variables to estimate the effects of policy; however, the findings are still relatively credible, reliable and important, as shown by the above analyses. Thus, we conclude that the notion that all the overuse of groundwater in Minqin is due to the irrational behaviors of the local people or natural factors like temperature, precipitation and evaporation may be wrong and should be studied more carefully. We find there is strong statistical evidence that government policy has positive influences on the overuse of groundwater, but contrary to what might be expected, the effects on the overuse of the groundwater of all three natural factors-temperature, precipitation and evaporation — are not very significant in our model. Although these findings cannot distinguish local effects from government policy effects and clearly tell us the degree to which government policy impacts the overuse of groundwater through influencing the behaviors of the local people and their operative level institutions or rules, using the Trend Analysis, we find these significant effects are strictly consistent with variations in the government policies effective at the county level of the Minqin basin. If other scholars still argue that local behaviors really impact the overuse of the groundwater in the Minqin basin, we can reply that that such behaviors have been strongly influenced by government policy, based on our findings. Indeed, this statement is also supported by the record of the county annals of Minqin, which claimed that before 1949, the peasants in Minqin had developed a very complex self-governance system to resolve the problems of the oases and it worked very well for over several hundred years [15]. After 1949, this system was abolished on the grounds that it was ignorant, uneducated and based on backward traditions [16]. This phenomenon was described by E. Ostrom [11] in the West and Central basin in California and bears repeating in the Minqin case: “After several decades of institutional change, the resulting institutional infrastructure that had been created represented a major investment that dramatically changed the incentives and behaviors of participants and the resulting outcomes. Each institutional change became the foundation for the next change" (1990: 141). The main difference in the Minqin basin is that these kinds of institutional changes were caused by the exogenous government actors, rather than the local people themselves, and the institutional diversity was diminished.

\section{Acknowledgements}

The study was supported by the National Natural Science Foundation of China (71073008). The author wishes to thank Professor Vincent Ostrom and Elinor Ostrom for their kind help. I benefited tremendously from their thoughtful comments and suggestions.

\section{REFERENCES}

[1] S. G. Reynolds (Food and Agriculture of United Nations), "Sustainable Development of Grassland Ecosystems: Two Case Studies from China," Proceedings of the International Symposium on Sustainable Development of Grassland Ecosystems, Inner Mongolia, 27-30 August 2001.

http://www.fao.org/ag/AGP/AGPC/doc/Present/China/chi na1.htm

[2] H. F. Lee and D. D. Zhang, "Perceive Desertification from the Lay Perspective in Northern China,” Land Degradation \& Development, Vol. 36, No. 5, 2004, pp. 529542. doi:10.1002/ldr.638

[3] L. Chen, Y. Qu, et al., "Water and Land Resources and Their Rational Development and Utilization in the Hexi Region,” Science Press, Beijing, 1992.

[4] J. Shi, "Effect of Rainwater Reuse on Ecological Environment in Shiyanghe Catchment," Proceedings of 7th International Rainwater Catchment System Conference, Vol. 1, No. 3, 1995, pp. 1-7.

[5] P. Harris, "Sixth and Final Report on Range Management,” Gansu Integrated Desert Control and Sustainable 
Agriculture, CPR/91/111, 1997.

[6] Joey, "Will the Desert Claim Minqin?” China Daily, 2004.

[7] X. Ma, B. Li, C. Wu, H. Peng and Y. Guo, "Predicting of Temporal-Spatial of Ground Water Table Resulted from Current Land Use in Minqin Oasis," Advances in Water Science, Vol. 14, No. 1, 2003, pp. 85-90.

[8] Y. Li and F. Chen, "Water Resources Sustainable Utilization Countermeasures in Minqin Basin of Gansu Province,” Journal of Mountain Science, Vol. 19, No. 5, 2001, pp. 465-469.

[9] D. N. Gujarati, "Basic Econometrics,” 4th Edition, Tata McGraw-Hill Publishing Company Limited, New York, 2003.

[10] H. Zhao, J. Ma, G. Zhu and X. Li, "The Study on the Change of the Groundwater Environment and Its Causes in the Minqin Basin, Gansu Province," Arid Zone Research, Vol. 21, No. 3, 2004, p. 212.

[11] E. Ostrom, "Governing the Commons the Evolution of Institutions for Collective Action," Cambridge University Press, Cambridge, 1990. doi:10.1017/CBO9780511807763
[12] P. A. Schrodt, "Meso-Level Regimes and Robust Plans," Comment 1 on Workshop in Political Institutions, Workshop in Political Theory and Policy Analysis, Indiana University, Bloomington, 1992.

[13] V. Ostrom, “Artisanship and Artifact,” In: McGinnis D. Michael, Ed., Polycentric Governance and Development, The University of Michigan Press, Ann Arbor, 1980, pp. 377-393.

[14] L. L. Kiser and E. Ostrom, "The Three Words of Action: A Metatheoretical Synthsis of Institutional Approaches," In: M. D. McGinnis, Ed., Polycentric Games and Institutions, The University of Michigan Press, Ann Arbor, 1982, pp. 56-88.

[15] L. Yang, "Scholar Participated Governance: Combating Desertification and Other Dilemmas of Collective Action,” Ph.D. Dissertation, Arizona State University, Phoenix, 2009.

[16] L. Yang, Z. Lan and J. Wu, "Roles of Scholars in the Practice of Combating-desertification: A Case Study in Northwest China,” Environmental Management, Vol. 46, No. 2, 2010, pp. 154-166. doi:10.1007/s00267-010-9534-y 